\title{
Mechanical Properties of Latex Modified High Performance Concrete
}

\author{
M. S. Shobha
}

\begin{abstract}
The inclusion of natural rubber latex into the Metakaoline blended concrete improves the performance properties of the concrete. Metakaoline in concrete reduces the porosity in the concrete on account of its pozzolanic reactions. Natural rubber latex modifies the concrete by improving the workability of concrete through ball bearing actions. The polymer latexes present in the natural rubber gets filled up in the pores in the paste structure thus forming a bond between the cement and aggregates in the concrete. This paper aims in presenting the optimum percentage weight natural rubber latex with Metakaoline to be made use in achieving the strengths at different water binder ratios to produce High Performance concrete.

Keywords: Natural rubber latex, High performance concrete, Metakaoline, water binder ratio, Aggregate binder ratio, compressive strength, flexure strengt..
\end{abstract}

\section{Introduction}

Use of pozzolana and polymers in concrete is in practice from long periods. The pozzolana like Metakaoline is used to replace cement to improve the concrete properties. The highly reactive Metakaoline is replaced cement in this investigation by various percentages of 5\%,10\%, 15\%, 20\% and 30\%. Along with metakaoline, the various percentage weights of natural rubber latex has also been made use. The water to binder ratio adopted is $0.3 \%, 0.325 \%, 0.35 \%, 0.375 \%, 0.4 \%$.

The use of super plasticizer is made to achieve the workability. The concept of using water binder ratio and compacting the concrete to minimize voids, making use of mineral admixtures will result in the type of concrete called High Performance Concrete. This paper presents the details of experimental results, incorporating natural rubber latex and Metakaoline based high performance concrete. High performance concrete now a day is essential in the construction of high rise buildings and the type of construction like nuclear power plants.

The inclusion of natural rubber latex in the concrete makes the concrete workable under lower water to binder ratios .This is interpreted in terms of improved consistency due to the ball bearing action of polymer particles.Tateyashiki, et al [1] proved by Zeta- potential that the consistency or fluidity is due to the ball bearing action of the polymer particles among cement particles. Ohama, Yashiko [2] in their literature opined that there is a noticeable increase in the tensile and flexure strengths but not many improvements in the compressive strengths of latex modified concrete.

Metakaoline is an artificial pozzolana produced by burning kaolinite clay with in a specific temperature range between $650^{\circ}-800^{\circ} \mathrm{C}$. The production processes is controlled to obtain higher purity and reactivity. Metakaoline comprises of Silica and alumina that react with calcium hydroxide formed during hydration of cement. Metakaoline reduces the $\mathrm{Ca}(\mathrm{OH})_{2}$ from the cement. Thus results in the formation of Calcium hydro Silicate and calcium alumino silicate which in turn is responsible in improving the strength. Wild et al [3] reported the results on strength development of concrete, where cement was partially replaced with Metakaoline. According to Wild the relative strength of concrete containing Metakaoline was found to increase with the increase in curing time. S.Wild, J.M.Khatib [4] in their report has mentioned that partial replacement by ultra-fine solids results in a reduction in the strength of pastes but an increase in the strength of concrete due to an improved transition zone.

Considering the useful properties of MK (Metakaoline) and NRL (natural rubber latex) it has been planned to make use of these materials in this investigation.

\section{Materials and methods}

Cement-Ordinary Portland Cement, OPC 53grade confirming to IS 12269-1987 was used. The properties of cement are presented in Table 1

Aggregates-Fine aggregates like river sand confirming to zone-II and crushed granite Coarse aggregates 20mm sizes confirming to IS 2386-1963 were used in mixing of concrete. Table 2 summarizes the aggregate properties. 
Water-Potable water is used for mixing the concrete.

Natural Rubber Latex (NRL)

Obtained from Hevea tree. It is a polymer consisting of repeating units of isoprene. Specific gravity of NRL is 1.06.It comprises $30-35$ rubber, wide range of diameter from $0.01-5 \mu \mathrm{m}, 0.1-2 \mu \mathrm{m}$ rubber phase.

\section{Metakaoline (MK)}

Metakaoline is obtained from 20 microns limited, Mumbai. Its chemical composition is presented in table 3.

\section{Experimental Procedure}

An experimental work has been planned to find the mechanical properties of metakaoline blended natural rubber latex modified high performance concrete. To prepare high performance concrete the mix proportions were obtained by adopting absolute volume method. The proportions are mixed in dry state and then the polymer admixture like NRL is mixed along with water. The mix is then filled into the moulds to test the various mechanical properties of the concrete. From the results obtained it was possible to find the optimum dosage of NRL to mix to concrete to achieve strengths. Similarly the dosage of MK was also found.

From this investigation the exact percentage of NRL and MK to be added to concrete is found. This can be obtained by mixing the percentage of NRL at different percentage by weights that is $0.5 \%, 1.0 \%, \& 1.5 \%$.Keeping $\%$ of NRL constant for each mix, the mixing and casting of cubes, cylinders and prisms are tried for different water to binder ratios of $0.3,0.325,0.35,0.375,0.4$.Thus the total number of cubes were 90 ,and prisms 90 were casted only for NRL mix. Also cubes, prisms of control mix were also casted. The percentage weight of Metakaoline replacing cement is also found by trying different $\mathrm{MK}$ ratios of 5\%,10\%, 15\%, 20\% and 30\%. The different strengths of NRL, MK mix at various W/B ratio is presented in Fig1, 2,3(a),3(b),3(c)\&4(a) \& 4(b).

Table-1-Properties of Cement

\begin{tabular}{|c|c|}
\hline Specific gravity & 2.5 \\
\hline Residue 325 mesh (\%max) & 0.5 \\
\hline Bulk Density(gm/ltr) & 300 \\
\hline Accelerated Pozzolanic Index, $\%$ & 97 \\
\hline $\mathrm{Sio}_{2}+\mathrm{Al}_{2} \mathrm{O}_{3}+\mathrm{Fe}_{2} \mathrm{O}_{3}$ & $96-98 \%$ \\
\hline $\mathrm{Loss}$ on Ignition & $<1 \%$ \\
\hline
\end{tabular}

Table-3 Composition of Metakaoline

\begin{tabular}{|c|c|}
\hline Specific gravity & 3.01 \\
\hline Specific Surface Area & $\begin{array}{c}316 \mathrm{~m}^{2} / \mathrm{kg} \text { By Blaine's } \\
\text { Air Permeability. }\end{array}$ \\
\hline Compressive strength of cement & \begin{tabular}{c} 
M days-44 Mpa 28 days-56 \\
\hline
\end{tabular} \\
\hline
\end{tabular}

Table -2 Properties of Aggregate

\begin{tabular}{|c|c|c|}
\hline Properties & Sand & Coarse Aggregate \\
\hline Specific gravity & 2.67 & 0.4 \\
\hline Fineness modulus & ---- & 7.5 \\
\hline Size of aggregates & 2.7 & $\begin{array}{c}\text { Passing through } \\
20 \mathrm{~mm} \text { sieve ,retained } \\
\text { on } 12.5 \mathrm{~mm} 50 \%, \text { on } \\
12.5-10 \mathrm{~mm} 50 \%\end{array}$ \\
\hline Elongation Index \% & River sand \\
& zone-II & 10 \\
\hline Flakiness Index \% & ---- & 9 \\
\hline
\end{tabular}




\section{Chemical Admixture}

Chemical admixture like Conplast $430(\mathrm{G})$ is made use to attain the homogeneity of the mix. Conplast $\mathrm{Sp}$ 430(G) complies with IS:9103:1999 and BS:5075 part 3.The specific gravity of Conplast Sp 430(G ) is 1.20.

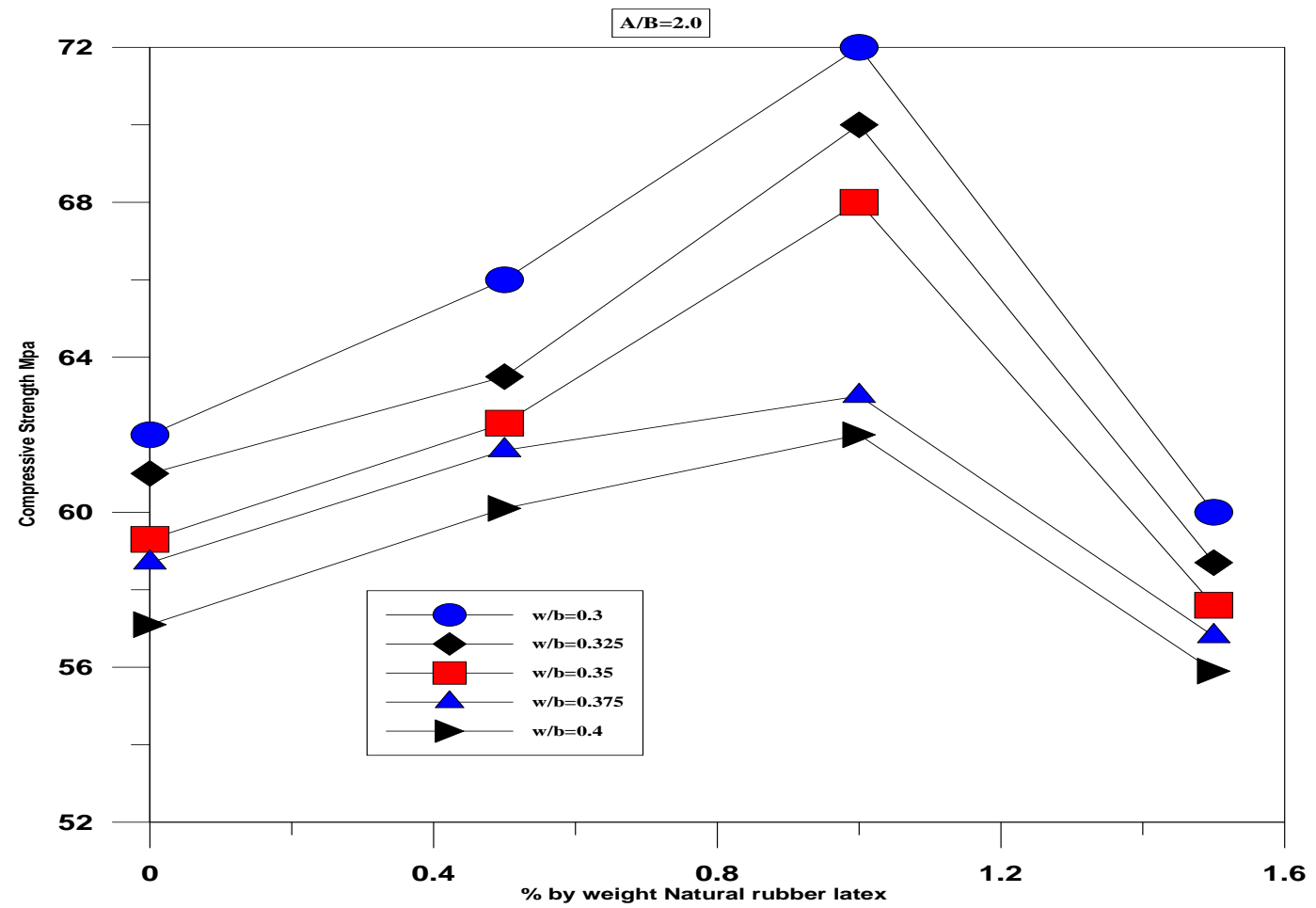

Figure 1.Compressive strength of Natural Rubber Latex modified High Performance concrete(RLHPC)

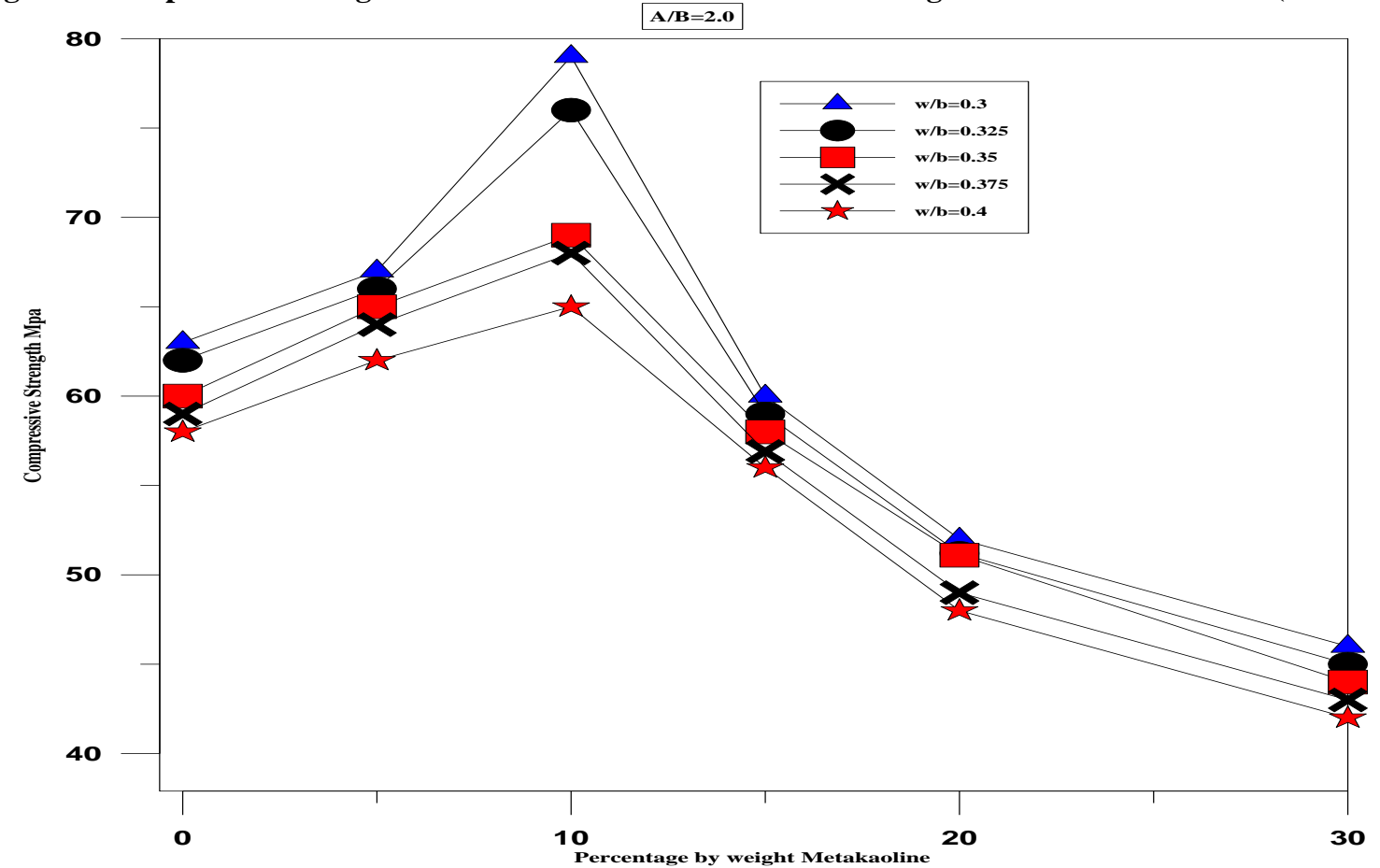

Figure 2.Compressive Strength of metakaoline modified High Performance Concrete(MKHPC) at different $\%$ by weight . 


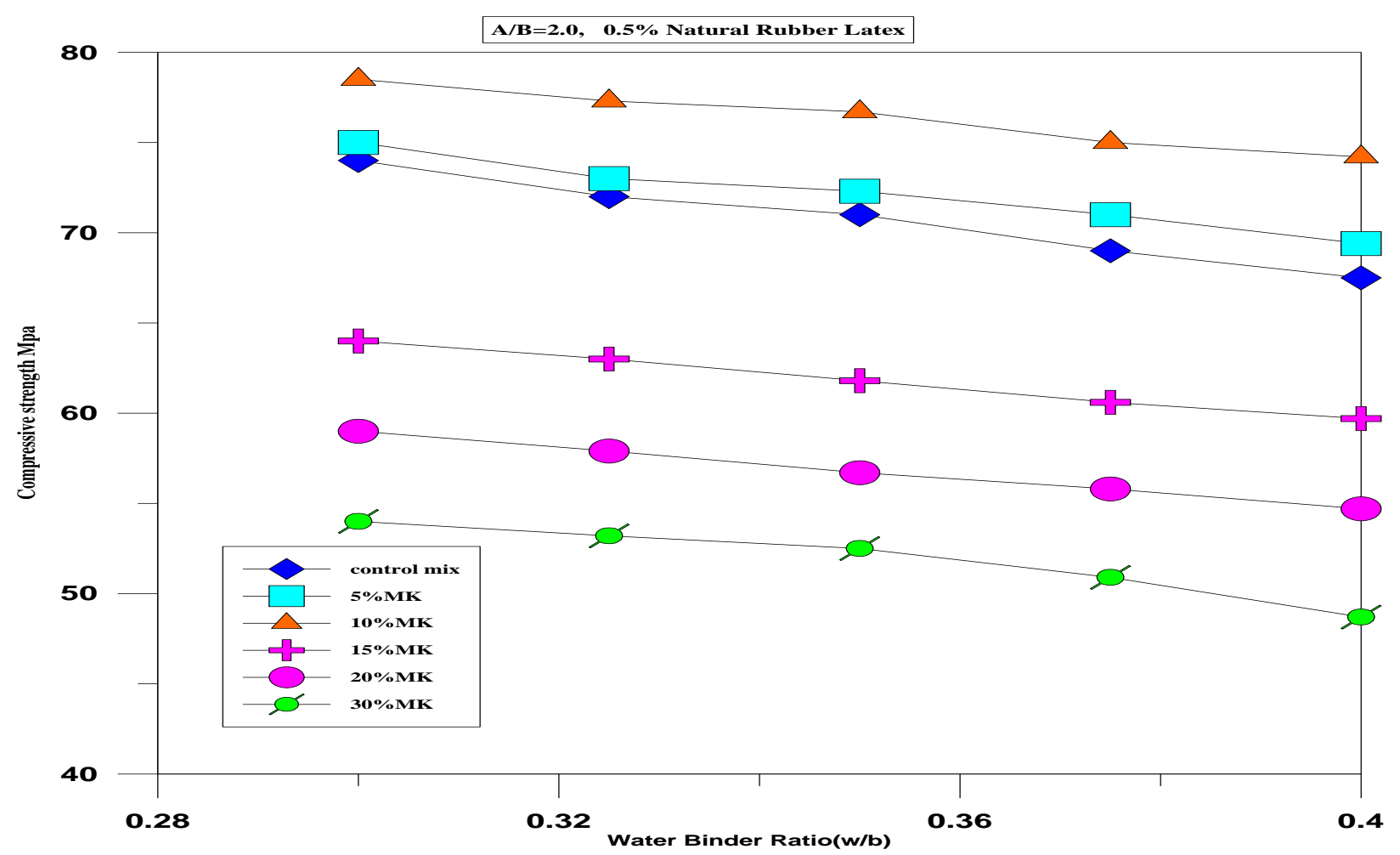

Figure 3(a) Compressive Strength of metakaoline blended natural rubber latex modified High Performance Concrete(RLMKHPC) - 0.5 Percent Natural Rubber Latex

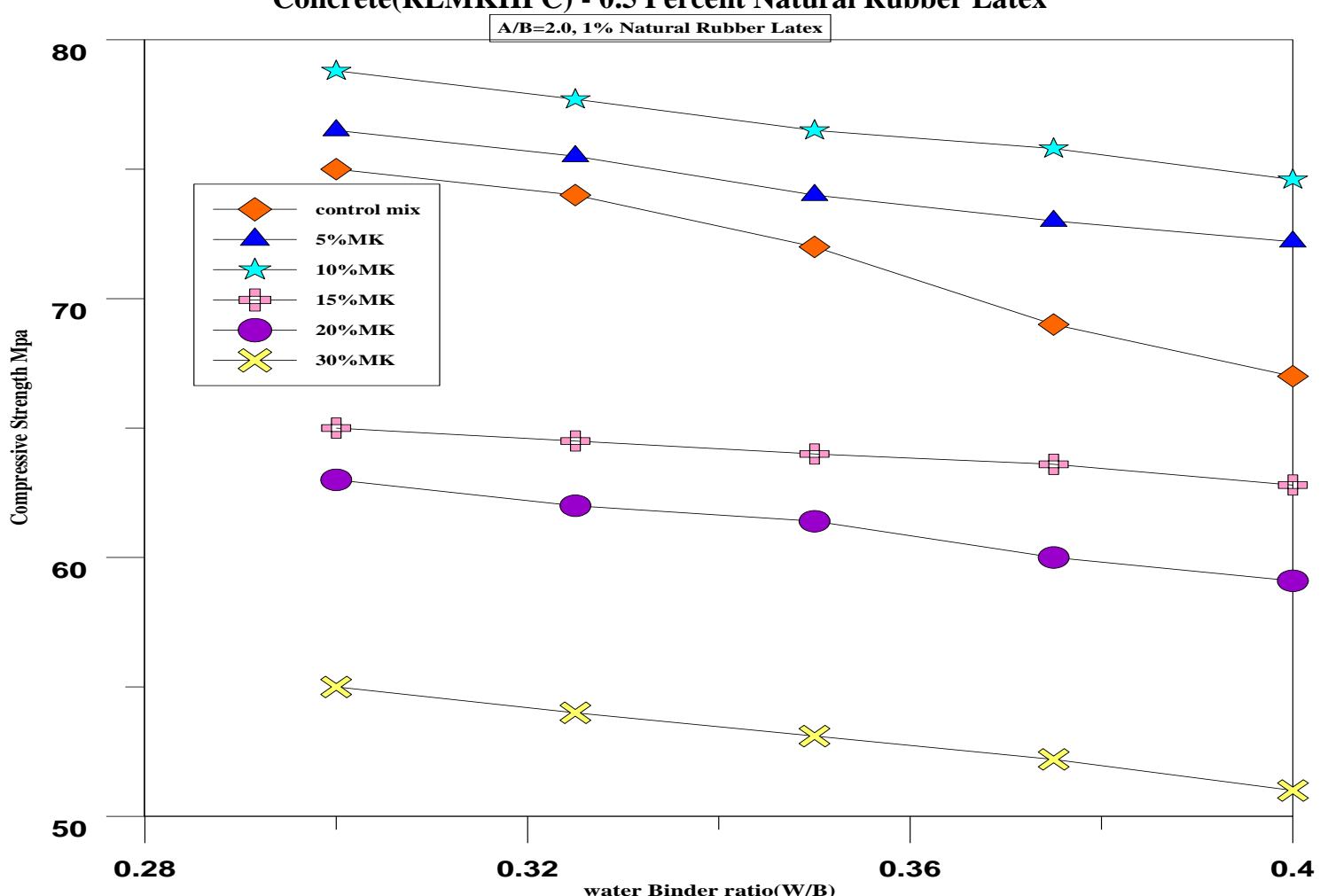

Figure 3(b) Compressive Strength of metakaoline blended natural rubber latex modified High Performance Concrete(RLMKHPC) - 1 \% by weight Natural Rubber Latex. 


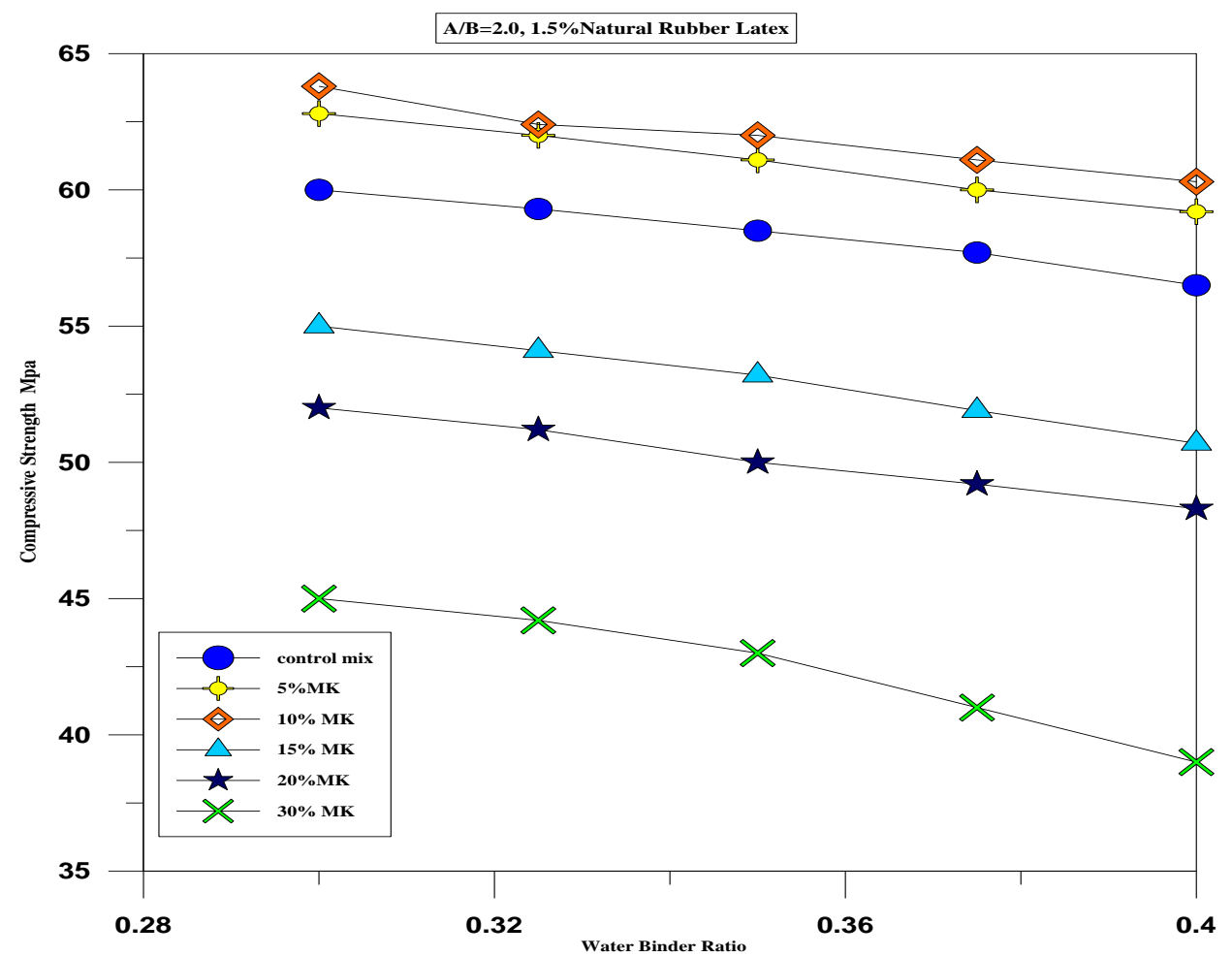

Figure 3(c) Compressive Strength of metakaoline blended natural rubber latex modified High Performance Concrete(RLMKHPC) - $\mathbf{1 . 5} \%$ by weight Natural Rubber Latex.

\section{Results and discussions}

It is observed from the fig1.that at $1 \%$ by weight natural rubber latex the compressive strength obtained is maximum compared to control mix. At $0.5 \%$ by weight of cement, rubber latex modified concrete exhibits progressive strength compared to control mix .Beyond $1 \%$ increase in the percentage weight of NRL, there is a down trend in the compressive strength. According to Ohama, in his literature, explained that there is an improvement in the tensile and flexure strength of latex modified concrete but not many improvements in the compressive strengths. In this investigation it has been observed that there is an increase in strengths of about 8 to $10 \%$ is observed at $1 \%$ natural latex modified concrete.

From Fig.2, it is observed that at $10 \%$ replacement of cement by metakaoline, the compressive strength reaches maximum value at water to binder ratio of 0.3.It can be observed from the graph that the strength decreases with increase in $\mathrm{w} / \mathrm{b}$ ratio marginally. Whereas when there is percentage increase in $\mathrm{MK}$, decrease in compressive strength of about $28 \%$ is observed from $10 \%$ to $30 \%$ replacement of cement by metakaoline.Hence it can be concluded that, if maximum strength is required at the same period of curing $10 \% \mathrm{MK}$ by weight of cement is appropriate.

It is observed from the Fig.3(a),3(b) and 3(c) the nature of the graph is linear plotted against different w/b ratios. The graph shows the variation of strength of the NRL modified metakaoline concrete at different $w / b$ ratios. It is observed that there are improvements in strength of the modified concrete. Except the graph 3(c) shows the decreasing trend in the compressive strength. This may be due to the increase in the addition of NRL to the concrete decreases the strength due to the increase in the water particles of the natural rubber latex.

Fig 4(a) shows the behavior of NRL modified high performance concrete. It is observed that the flexure strength of the NRL modified concrete is maximum compared to the control mix. This explains that, the use of the polymer latex in the concrete improves the flexure strength. From Fig 4(b) it is observed that there is a marginal increase in the strength under flexure when metakaoline is made use in the concrete when compared to the concrete with natural rubber latex Fig 4(a). 


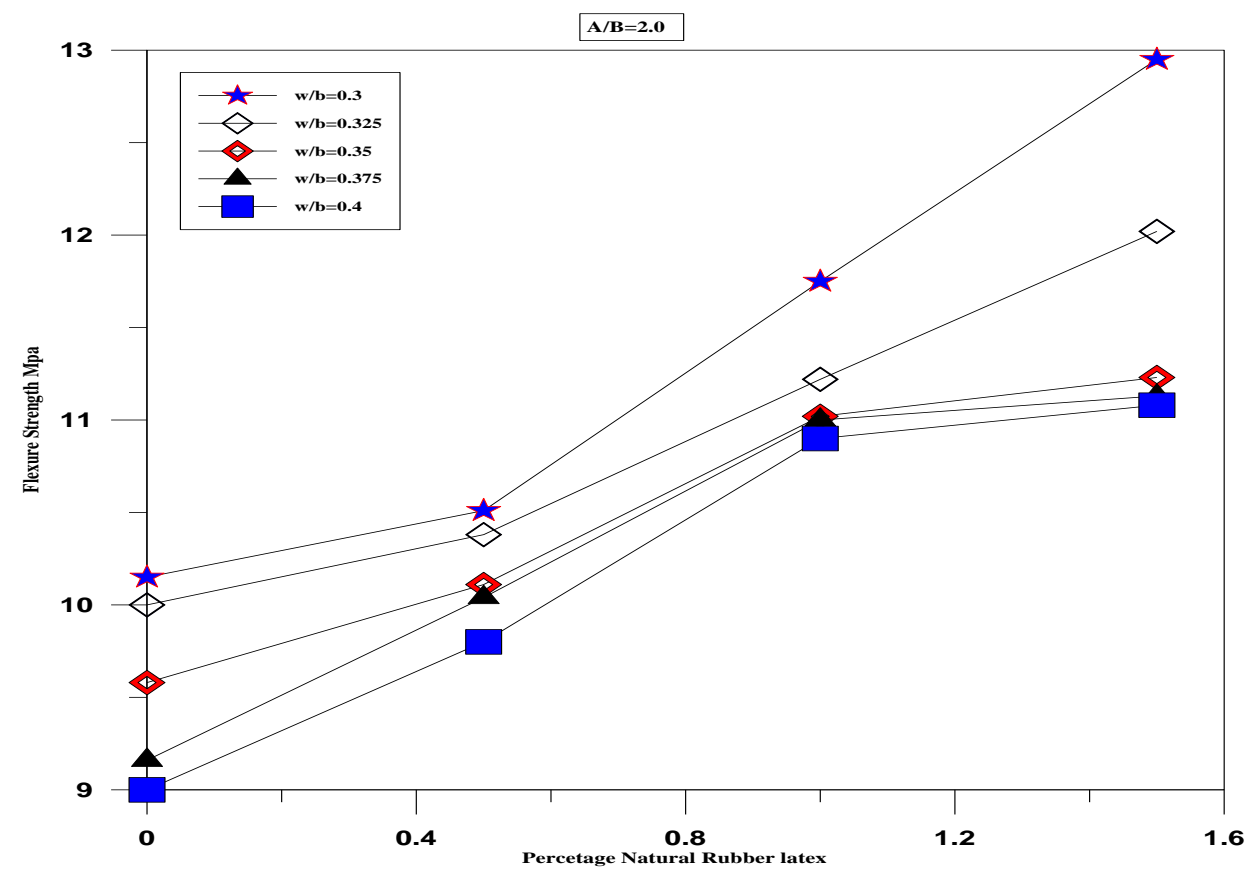

Fig 4 (a) Behavior of Natural Rubber latex Modified Concrete in Flexure.

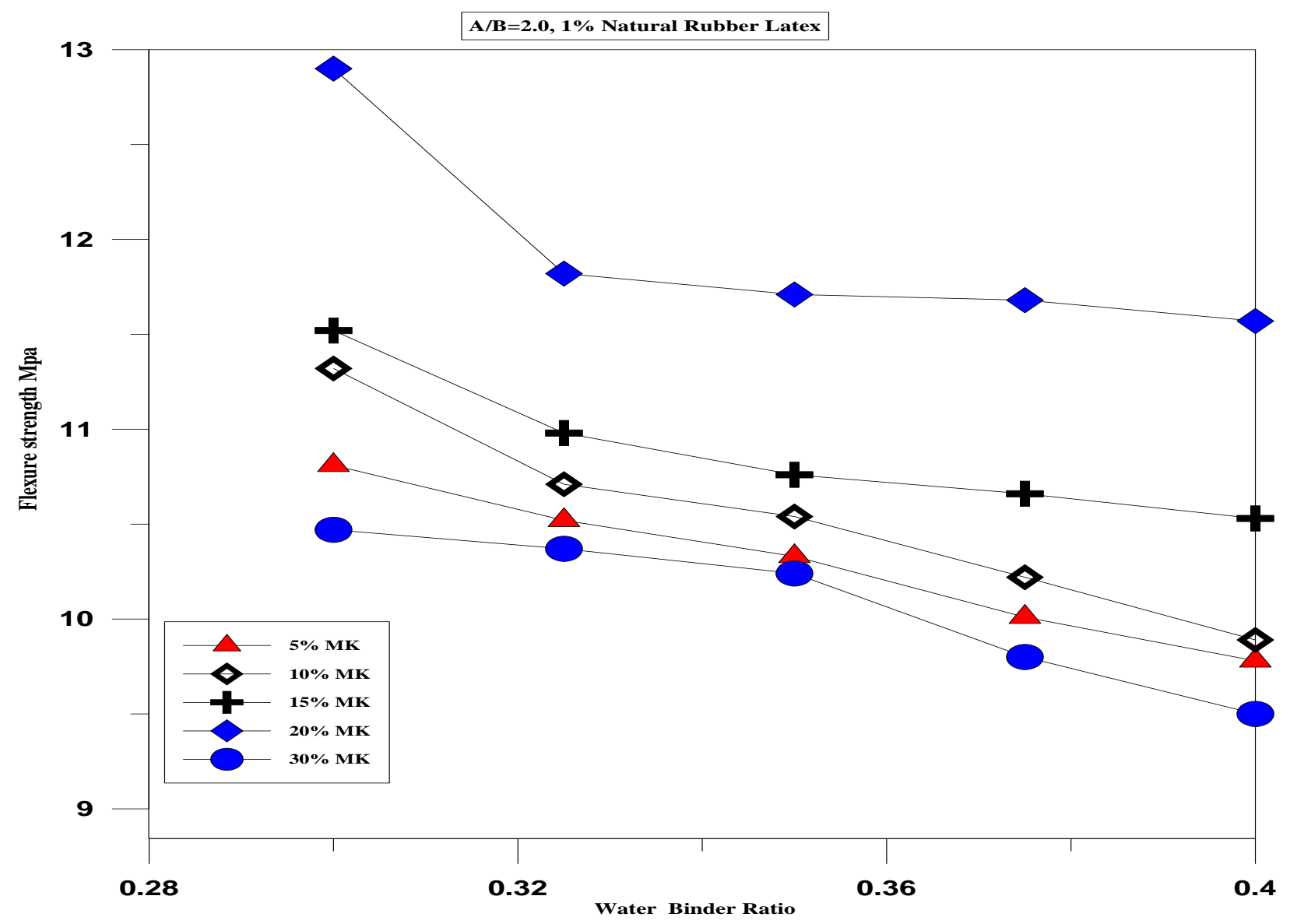

Fig4(b) Behavior of Natural Rubber latex metakaoline modified Concrete in Flexure. 


\section{Conclusions}

Following are the conclusions drawn from the this investigation,

- The optimum dosage of natural rubber latex is found to be $1 \%$ by weight of cement in the concrete.

There is an improvement in the compressive strength at $1 \%$ compared control mix, $0.5 \%$ and $1.5 \%$ by weight.

- It is observed that at a water to binder ratio of 0.3 the concrete attains maximum strength.

- The replacement of cement by metakaoline is found to be $10 \%$. There is improvement in strengths at this percentage replacement by metakaoline.

- Replacing the cement by MK and inclusion of NRL not only improves the mechanical properties but also makes the construction economical.

- Making use of both MK and NRL in concrete there is further improvements in the mechanical properties.

\section{References}

[1]. Mohammad Ismail, Bala Muhammed,Abdirahma AliYussuf, Mechanical Capabilities and fire endurance of Natural Rubber latex ,Canadian journal of Civil Engineering, 4 July 2011, Volume 38,pp 661-668.

[2]. T.S.Nagaraj,K.T.Sudara Raja Iyengar and B.Kameshwara Rao, Super Plasticized natural rubber latex Modified concrete, Cement and Concrete Research, October 2010, Volume 18, issue 1, pp. 138-144.

[3]. Khatib, J.M. and Wild S.Pore size distribution of Metakaoline paste, Cement and Concrete research ,August 1996,vol 26(10), pp. 15451553.

[4]. Wild, S.KhatibJ.M.and Jones A., Relative Strength, Pozzolanic activity and Cement Hydration in Super plasticized Metakaoline Concrete, Cement and Concrete Research, August 1996,26(10,)pp 1537-1544.

[5]. Natural Rubber from Wikipedia, the free encyclopedia

[6]. Ohama, Yoshihiko, Hand book of polymer-modified concrete and mortars, published in United States of America, Noyes Publications, August 1994.

[7]. F. Crucio,B.A.De Angelis, Metakaoline as a pozzolanic micro filler for high performance mortars, Cement and concrete research, March 1998,volume 28,No.6.pp 803-809.

[8]. Luc Courard,Annie Darimont, Durability of mortars modified with metakaoline, cement and concrete research, February 2003, volume 33, pp 1473-1479.

[9]. PhilippeJ.P.Gleize,Martin Cyr, Effects of metakaoline on autogenous shrinkage of cement pastes, cement and concrete composites, October 2006, volume 29,pp. 80-87.

[10]. C.S.Poon,L.Lam,S.C.Kou,Y.L.LWong,RonWong,Rate of pozzolanic reaction of metakaoline in high performance cement pastes, cement and concrete research, June 2001, volume 31,pp.1301-1306.

[11]. Bala Muhammed,Mohammed Ismail, Performance of natural rubber latex modified concrete in acidic and sulphated environments, Construction and Building Materials, December 2012, vol,31,pp. 129-134.

[12]. Bala Muhammed, Technology ,Properties and application of NRL Elastomers, INTECH open science, Chapter 11. 